\title{
O diálogo como fundamento político da democracia
}

\section{Luiz Roberto Gomes}

Professor da Universidade Federal de São Carlos

\section{Resumo}

O artigo aborda o tema do diálogo como fundamento político da democracia. Trata-se de um texto de homenagem, que procurou revisitar, no âmbito das reflexões proferidas e publicadas pelo Prof. Pedro Goergen, a temática em questão. A exposição da argumentação percorre dois caminhos: 1) a perspectiva dialógica da Teoria do Agir Comunicativo de Habermas e 2) o diálogo como fundamento político da democracia. $\mathrm{O}$ texto encerra-se com o desafio da consciência individual e coletiva, da convivência, do "entender-se", na vida democrática. Desafio este, que segundo Goergen (2010) pode e deve ser enfrentado dialogicamente.

Palavras-chave: Diálogo; Democracia; Habermas.

\begin{abstract}
The article discusses the theme of dialogue as the basis of democracy. It is a homage text, which sought to revisit in the context of spoken reflections and published by Prof. Peter Goergen, the theme in question. Exposure argument runs both ways: 1) the dialogic perspective of Communicative Action Theory of Habermas and 2) the political dialogue as a foundation for democracy. The text concludes with the challenge of individual and collective consciousness, coexistence, and the "be understood" in democratic life. This challenge, which according to Goergen (2010) can and should be addressed dialogically.
\end{abstract}

Keywords: Dialogue; Democracy; Habermas.

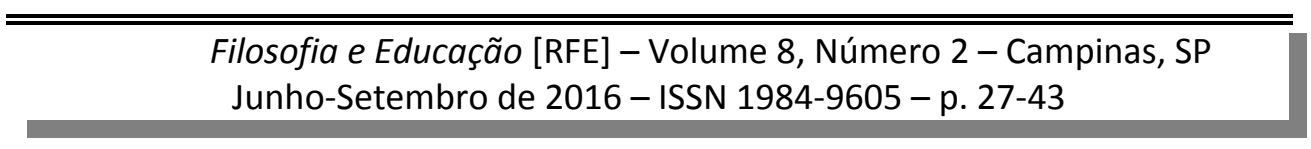


[...] o discurso democrático ou dialógico entre o eu e o outro é estruturalmente necessário e inarredável para se chegar a elementos comuns sobre os quais se possam assentar legitimadamente o entendimento $e$ a convivência humana.

Goergen (2008, p. 36)

\section{Introdução}

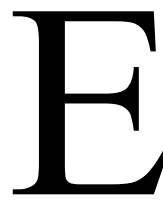

ntre as diversas oportunidades de aprendizagem que tive ao lado do Prof. Pedro Goergen, seja por ocasião do curso de doutorado em Educação na Unicamp, seja pela convivência e amizade que perdura até hoje, a perspectiva de uma mentalidade aberta à aprendizagem e à crítica, no sentido de Popper, sempre me pareceu digno de reconhecimento de alguém comprometido com a educação enquanto um Bem Público. Para além da erudição, percebida na forma como ele lida com os conceitos oriundos de teorias filosóficas complexas, o que sempre foi marcante no Prof. Pedro é a atitude política em pensar, dialogicamente, a educação brasileira e a formação de seus intelectuais orgânicos.

A forma como Prof. Pedro estabeleceu a aproximação com a tradição intelectual da Teoria Crítica da Sociedade merece destaque, pois independentemente do autor e da filiação destes às escolas de pensamento: Marx, Benjamin, Adorno, Horkheimer, Marcuse, Habermas, Honneth, entre outros, sempre foram considerados nas suas significativas contribuições, principalmente nos aspectos concernentes ao potencial crítico de suas análises, ora convergentes e ora divergentes em certos aspectos, mas que não são necessariamente excludentes. Essa capacidade de dialogar, bastante rara hoje em dia, decorre, entre outras coisas, de uma formação voltada à compreensão de uma das categorias centrais do pensamento habermasiano: 
a racionalidade comunicativa, que se desenvolve, fundamentalmente, pelos argumentos capazes de reconhecer, intersubjetivamente, as pretensões de validade apresentadas na forma de um discurso (HABERMAS, 1999a, p. 36).

Entre as ideias do pensador alemão Jürgen Habermas, competentemente interpretadas e trabalhadas pelo Prof. Pedro em suas pesquisas e produção intelectual, eu destacaria o tema do diálogo e sua articulação política com o processo de constituição das sociedades democráticas, como algo que merece uma reflexão abrangente por parte das pessoas politicamente envolvidas com a formação da sociedade brasileira, pois "o diálogo representa, antes de tudo, a organização de um espaço público no qual possam ser discutidas as novas questões relativas aos sentidos éticos, políticos e culturais que servem de orientação ao agir das pessoas em sociedade" (GOERGEN, 2010, p. 43).

A exposição da argumentação a ser desenvolvida nesse texto obedecerá duas linhas principais de raciocínio: 1) a perspectiva dialógica da Teoria do Agir Comunicativo de Habermas e 2) o diálogo como fundamento político da democracia.

\section{A perspectiva dialógica da Teoria do Agir Comunicativo}

Na Teoria do Agir Comunicativo de Jürgen Habermas, publicada em 1981, o diálogo como expressão da racionalidade comunicativa, estruturado por argumentos e baseado em pretensões de validade, assume um sentido próprio quanto aos fundamentos epistemológico, ético e político ${ }^{1}$. O referido autor baseou-se nos aspectos gerais do paradigma linguístico, sobretudo os

\footnotetext{
${ }^{1}$ Para uma análise mais abrangente do referido assunto, cf. os capítulos 1 - "Educação e Diálogo" (Pedro Goergen), e 2 - "Agir Comunicativo, Diálogo e Educação" (Luiz Roberto Gomes), in Goergen, 2010.
}

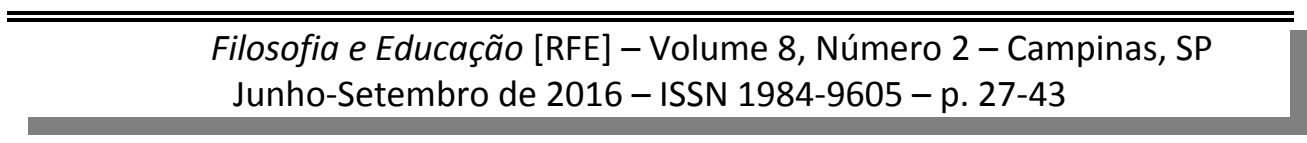


estudos desenvolvidos pela filosofia analítica, em especial os da "teoria do significado", como ponto de partida para a elaboração de sua Teoria. Nesse sentido, apoiado na concepção moderna de linguagem e formação de Humboldt, ele serve-se dos elementos teóricos que compõem a filosofia da linguagem, admitindo os avanços promovidos pelo "giro linguístico", e estabelece uma interlocução com os principais autores dessa linha de pensamento (Humboldt, Wittgenstein, Austin, Searle, Bühler, Frege, Heidegger, Apel, Chomsky, Gadamer, entre outros). Esse esforço teórico lhe permite apontar uma mudança de paradigma filosófico ao entender que "a racionalidade tem menos a ver com o conhecimento, ou com a aquisição de conhecimento, e mais com a forma com que os sujeitos capazes de linguagem e de ação fazem uso do conhecimento" (HABERMAS, 1999a, p. 24). Trata-se, portanto, do entendimento de dois paradigmas de pensamento filosófico distintos, na sua forma de conceber a realidade: o paradigma da filosofia da consciência ou do sujeito, que corresponde ao modelo da racionalidade cognitivo-instrumental, e o paradigma da filosofia da linguagem ou da intersubjetividade, que corresponde ao modelo da racionalidade comunicativa.

Com tal entendimento, Habermas aponta a possibilidade de enfrentamento de um dos problemas centrais do pensamento ocidental, a saber: a dicotomia da relação "consciência e mundo", "sujeito e objeto", “objetividade e verdade". Ao adotar o paradigma intersubjetivo da filosofia da linguagem, renunciando, desta forma, à possibilidade do acesso direto aos fenômenos da consciência ou aos objetos externos, o conhecimento passa a depender das pretensões de validade estabelecidas por meio das expressões e representações linguísticas compartilhadas. Isso implica a ideia de que a verdade é uma pretensão universal de validade inerente à 
linguagem, e que precisa ser enunciada e construída dialogicamente na forma de argumentos.

Nessa linha de raciocínio, as formas de interação social se conectam às formas de reprodução social: a reprodução cultural, a integração social e a socialização, sendo a cultura, a sociedade e a personalidade os três componentes estruturais correspondentes ao "mundo da vida". A cultura é o acervo do saber em que os participantes da comunicação se abastecem de interpretações para entender-se sobre algo no mundo. A sociedade compreende as ordens legítimas segundo as quais os participantes da comunicação regulam suas pertenças a grupos sociais, assegurando, com isso, a solidariedade. E a personalidade serve como termo técnico para designar as competências adquiridas no sentido de tornar um sujeito capaz de falar e agir, colocando-o em condições de participar de processos de entendimento e para afirmar neles sua própria identidade (HABERMAS, 1999b).

O conceito de ação comunicativa é concebido por Habermas como um agir linguístico estabelecido entre duas ou mais pessoas que, ao conversarem entre si sobre algo no mundo, levantam, com seus atos de fala, pretensões de validade. A linguagem como mediação e o diálogo como procedimento constroem saberes e formas de integração social. Sob o aspecto funcional do entendimento, a ação comunicativa serve à tradição cultural e à renovação do saber cultural; sob o aspecto da coordenação da ação, serve à integração social e à criação de solidariedade; e finalmente, sob o aspecto de socialização serve à formação de identidades pessoais (HABERMAS, 1999b).

Habermas (1999b) concebe a interação social em dois tipos distintos de ação: a ação comunicativa e a ação estratégica. Mesmo que de forma intuitiva, os agentes da sociedade acabam assumindo ou uma atitude

\begin{tabular}{c}
\hline Filosofia e Educação [RFE] - Volume 8, Número 2 - Campinas, SP \\
Junho-Setembro de 2016 - ISSN 1984-9605 - p. 27-43
\end{tabular}


orientada ao êxito (estratégica), ou uma atitude orientada ao entendimento (comunicativa). A partir dessa premissa, o autor compreende a sociedade como o mundo da vida de determinado grupo social que coordena suas ações comunicativamente e, por outro lado, um sistema que regula a si mesmo por meio de ações funcionais estrategicamente articuladas. O mundo da vida e o sistema representam, portanto, duas formas distintas de interação social que se expressam ora como integração social, realizada a partir da reprodução simbólica do mundo da vida, ora como integração funcional, realizada a partir da reprodução material necessária à sobrevivência e à conservação do sistema.

Por meio da racionalidade comunicativa, Habermas desenvolve uma teoria segundo a qual, ao ingressar num contexto argumentativo, todo e qualquer agente torna-se responsável por seus argumentos, que ficam expostos permanentemente à crítica. Isso significa que a competência comunicativa implica um processo permanente e responsável de busca da verdade, de modo que todo o agir comunicativo também signifique uma práxis educativa ao determinar a formação das ações humanas. Para Habermas, os saberes, por mais falíveis que possam ser, só assumem a condição de saberes válidos quando são reconhecidos e justificados intersubjetivamente por argumentos racionais.

O que pesa sobre as decisões dos participantes de um discurso prático é a força de obrigatoriedade daquela espécie de razões que, em tese, podem convencer a todos igualmente, não só as razões que refletem as preferências individuais das pessoas, mas as razões, que todos os participantes podem descobrir juntos, sobre a prática a ser adotada para atender aos interesses de todos. Os participantes, no momento mesmo em que iniciam tal prática argumentativa, têm de estar dispostos a atender à exigência de cooperar uns com os outros na busca das "melhores" razões; e,

\begin{tabular}{l}
\hline \hline Filosofia e Educação [RFE] - Volume 8, Número 2 - Campinas, SP \\
Junho-Setembro de 2016 - ISSN 1984-9605 - p. 27-43
\end{tabular}


mais ainda, têm de estar dispostos a deixar-se afetar e motivar, em suas decisões afirmativas e negativas, pelos argumentos e somente por eles.

Agora, qual o potencial crítico que uma perspectiva dialógica como a proposta por Habermas teria, para o enfrentamento dos desafios da sociedade atual? A resposta para essa questão pode ser encontrada nas diversas análises desenvolvidas por Pedro Goergen, das quais destacamos:

Na sociedade, os homens estão tratando constantemente de orientar-se no mundo, de organizar os mapas de seus caminhos. Um dos mais desconcertantes problemas dessa tarefa na atualidade é a natureza da sociedade imanejavelmente grande e mutante que não permite uma orientação segura. No interior desse cenário merecem destaque dois aspectos que interessam sobremaneira ao nosso contexto. O primeiro é a já mencionada natureza fluida da realidade, em que a solidez e a estabilidade como referências de comportamento cedem espaço às incertezas [...]. O segundo ponto é a mudança da sociedade dividida em Estados Nacionais, separados entre si por fronteiras bastante rígidas, para uma sociedade globalizada, transnacional, em que se encontram e passam a viver lado a lado culturas diferentes e cujo entendimento é condição fundamental para a vida social contemporânea. Essa inescapável necessidade de relação entre as culturas alçou ao primeiro plano o conceito de Verständigung, que numa versão literal significa 'entendimento', mas que no nosso contexto se traduz melhor pela dinâmica verbal de 'entender-se' (GOERGEN, 2010, p. 34-35).

Para além do potencial crítico, o entendimento a ser alcançado mediante o diálogo desafia as diversas instâncias da sociedade, pois ainda não há, segundo Goergen (2010, p. 53), um “diálogo político, econômico, 
jurídico, cultural ou educacional que permita vislumbrar a organização de um espaço público" em que possam ser discutidas as questões emergentes da nossa sociedade atual. Ainda conforme as instigantes provocações do professor Pedro, "o único caminho possível parece ser o da construção democrática de uma nova base de entendimento que sirva de parâmetro comum ao agir individual e social" (Goergen, 2010, 40). Sem dúvida, uma das formas de institucionalização do diálogo deve ocorrer na esfera política, aspecto esse que, segundo Habermas (2003), se configura como fundamento da democracia.

\section{O diálogo como fundamento político da democracia}

Nos estudos de teoria política, Jürgen Habermas confere à democracia um sentido próprio. Segundo o autor, a democracia se consolida a partir da ação efetiva das instituições democráticas e do papel dos cidadãos exercido no contexto do espaço público e da sociedade civil. Não se trata de um modelo normativo de democracia, centrado no Estado, ou de um modelo representativo que restringe a participação e o engajamento político à atuação de lideranças, mas de um modelo procedimental de democracia que considera como instância de legitimação a "razão" deliberada comunicativamente pela sociedade civil.

Para Habermas (2003b, p. 18), “o processo da política deliberativa constitui o âmago do processo democrático". O autor entende que a legitimidade da ação política deve deslocar-se do modelo inscrito na representação de uma "vontade geral" para o modelo da "deliberação" oriundo do processo racional de formação da vontade dos cidadãos. Nas palavras de Habermas: 
A política deliberativa obtém sua força legitimadora da estrutura discursiva de uma formação da opinião e da vontade, a qual preenche sua função social e integradora graças à expectativa de uma qualidade racional de seus resultados. Por isso, o nível discursivo do debate público constitui a variável mais importante. (HABERMAS, 2003b, p. 27-28)

Note-se que a ênfase da concepção deliberativa volta-se para o processo de argumentação, próprio da formação discursiva (dialógica) da opinião pública e da vontade, e que passa a ser determinante para a tomada de "decisões coletivas". Em outras palavras, a legitimidade do poder político de decisão deve estar permanentemente ancorada no processo de deliberação pública e que, segundo Habermas (2003a, p. 210), pode ser esquematizado da seguinte forma:

Modelo do processo de formação política racional da vontade

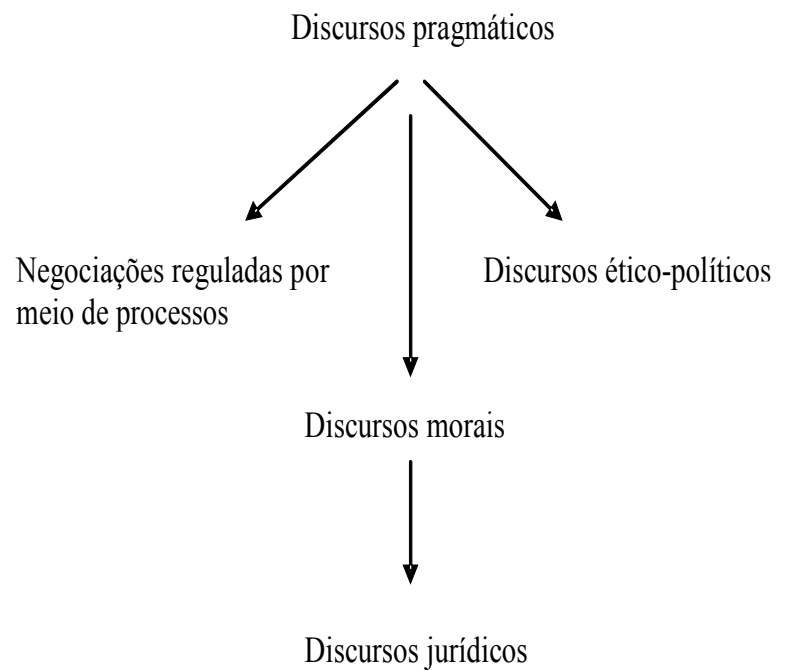

Filosofia e Educação [RFE] - Volume 8, Número 2 - Campinas, SP Junho-Setembro de 2016 - ISSN 1984-9605 - p. 27-43 
O esquema indica que, no modelo procedimental, a formação racional da opinião e da vontade apresenta-se como uma rede de discursos e negociações que derivam da própria lógica discursiva. Admitida a complexidade das questões políticas, o processo de deliberação democrática procura estabelecer um nexo interno e simultâneo entre as considerações pragmáticas, as negociações reguladas por processos próprios, os discursos ético-políticos, os discursos morais, os discursos jurídicos, sempre com o propósito de chegar, por meio da deliberação discursiva, a resultados racionais

A deliberação discursiva (dialógica) permite que o processo intersubjetivo se deixe compreender tanto em seu sentido cognitivo como no prático. A dimensão cognitiva do discurso possibilita a realização de um acordo racional alcançado por intermédio da força do melhor argumento, e a dimensão prática do discurso produz as condições para o exercício da autodeterminação racional intersubjetiva do entendimento. Trata-se, portanto, de um processo em que são validadas apenas as normas de ação aceitas pelos participantes de um discurso racional.

Tais pressupostos nos permite dizer que, para Habermas (2003a), o modelo procedimental de democracia consiste na autodeterminação pública de cidadãos que deliberam, a partir do processo racional de formação discursiva, a respeito da opinião e da vontade da sociedade civil. É dessa forma que o fluxo comunicativo da esfera pública informal converte-se, formalmente, em uma decisão política institucionalizada, com possibilidades reais de transformação do poder produzido comunicativamente em poder aplicável administrativamente, já que, segundo Habermas (2003b, p. 56), 
Os fluxos comunicacionais da esfera pública política estão especialmente expostos à pressão seletiva da inércia social; todavia a influência gerada por este caminho só pode transformar-se em poder político quando passar através das comportas do processo democrático e do sistema político em geral, instaurado na forma de Estado de Direito.

Habermas argumenta que a passagem de uma instância a outra não ocorre de forma mecânica, mas pelo medium do direito que detém a capacidade de articular, simultaneamente, tanto os aspectos administrativos do sistema como os fluxos comunicativos do processo de formação coletiva da opinião e da vontade da sociedade civil. Nesse sentido, Pedro Goergen esclarece:

Por isso, nem o parlamento nem as instituições jurídicas podem ser consideradas o fundamento da democracia. Apesar de sua importância, estas estruturas institucionais apenas canalizam (ou deveriam canalizar) a vontade popular, elaborada no âmbito dos debates realizados no espaço público. Portanto, a formação da vontade política se realiza em espaços e processos não necessariamente institucionalizados politicamente. Aqui podemos entrever, com bastante clareza, a importância de ambientes não estritamente políticos para a política. Papel relevante cabe, nesse contexto, aos espaços da família, dos grupos de amigos, dos meios de comunicação e da educação formal (GOERGEN, 2008, p. 39).

Uma compreensão ampliada de ação política pressupõe a distinção necessária entre os domínios administrativo e comunicativo que envolve o sistema político como um todo, de modo que o poder administrativo só pode 
funcionar de maneira legítima se for alimentado constantemente pelos fluxos comunicativos contidos na esfera pública, nas associações e na esfera privada. Sabemos, no entanto, que a abertura do sistema político ao mundo da vida não ocorre de forma espontânea, devido às formas dominantes de resistência dos interesses institucionais corporativos, que acabam distorcendo todo o processo político.

No âmbito da exigência de legitimidade comunicativa das ações políticas administrativas, Habermas desenvolve os conceitos de esfera pública e sociedade civil, com o propósito de refletir sobre as formas de circulação de poder no âmbito da sociedade e, ainda, sobre os obstáculos que os fluxos comunicativos precisam enfrentar para transformar o poder comunicativo em poder administrativo.

A esfera pública, que não pode ser concebida como uma instituição, nem como sistema ou organização, pois não há uma estrutura normativa de atuação, é o espaço da opinião pública que funciona como

uma rede adequada para a comunicação de conteúdos, tomadas de posição e opiniões, e nela os fluxos comunicacionais são filtrados e sintetizados, a ponto de se condensarem em opiniões públicas enfeixadas em termos específicos comunicacionais (HABERMAS, 2003b, p. 92).

Trata-se de um ambiente comunicativo orientado pelo entendimento, e que reproduz simbolicamente o mundo da vida na forma de uma grande "caixa de ressonância" das vontades e opiniões da sociedade civil.

A sociedade civil, por sua vez, é constituída pela trama não-estatal e não-econômica, ancorada nas estruturas de comunicação da esfera pública e nos componentes sociais do mundo da vida. Refere-se às associações, 
organizações e movimentos sociais, com capacidade de influência sobre a esfera pública política (HABERMAS, 2003b, p. 99).

Mesmo reconhecendo os limites de ação de uma esfera pública baseada na sociedade civil, Habermas considera que os fluxos comunicativos oriundos dessas estruturas podem influenciar a formação da opinião e da vontade que se institucionaliza no complexo parlamentar, pois:

Na perspectiva de uma teoria da democracia, a esfera pública tem que reforçar a pressão exercida pelos problemas, ou seja, ela não pode limitar-se a percebê-los e a identificá-los, devendo, além disso, tematizá-los, problematizá-los e dramatizá-los de modo convincente e eficaz, a ponto de serem assumidos pelo complexo parlamentar. [...] a capacidade de elaboração dos próprios problemas, que é limitada, tem que ser utilizada para um controle ulterior do tratamento dos problemas no âmbito do sistema político. (HABERMAS, 2003b, p. 91)

Como podemos notar, a esfera pública exerce uma função social decisiva no sistema político, pois quanto mais ativa, maior o volume dos fluxos comunicativos que penetram no sistema administrativo. Todavia, não se trata de uma passagem livre de obstáculos, pois o Estado de direito é dotado de códigos especializados dos sistemas de ação auto-regulados, que acabam dificultando a livre circulação da linguagem comum dos atores sociais. Daí a importância do direito, enquanto "transformador" ou "conversor" da linguagem dos parlamentos e tribunais para o cotidiano da vida social.

Para uma explicação mais clara desses obstáculos, Habermas recorre ao modelo desenvolvido pelo cientista político Bernhard Peters (1993), com 
o propósito de explicitar o processo de circulação do poder regulado pelo Estado de direito. Segundo essa proposta, os processos de comunicação e de decisão do sistema político constitucional são ordenados no eixo centroperiferia e estruturados por intermédio de um sistema de comportas, extremamente decisivos para a regulação dos fluxos da comunicação.

O centro do sistema político é formado pela administração (incluindo o governo), o Judiciário e a formação democrática da opinião e da vontade (incluindo as corporações parlamentares, as eleições políticas e os partidos políticos). Nas margens da administração está a periferia, formada por instituições variadas (universidades, igrejas, associações, fundações, etc.). Essa forma de ordenamento social exige a legitimidade social dos fluxos comunicacionais, que partem da periferia e atravessam as comportas dos procedimentos próprios da democracia e do Estado de direito, antes mesmo de chegar ao complexo parlamentar ou aos tribunais.

A metáfora utilizada por Habermas para explicar a passagem de uma instância a outra é a imagem de uma eclusa, em que os fluxos comunicativos necessitam acumular volume suficiente para alcançar o patamar mais alto do centro de decisão. Em outras palavras, a passagem das redes periféricas da esfera pública para a esfera pública institucionalizada está condicionada à capacidade comunicativa de intervenção social. É nesse contexto que Habermas localiza o potencial emancipatório do direito, pois ele detém a capacidade de traduzir os fluxos comunicativos, sendo de um lado a voz da administração e de outro a voz do processo de formação coletiva da opinião e da vontade.

Assim, a forma de organização democrática proporciona um espaço para que a esfera pública e a sociedade civil possam, pela mediação da linguagem do direito, exercer um papel social cada vez mais relevante, no sentido de trazer à arena política os problemas que afetam a sociedade como

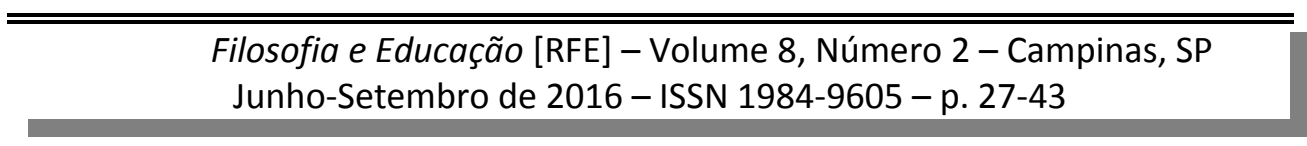


um todo. Trata-se da capacidade de influenciar, dialogicamente, o próprio complexo parlamentar, obrigando o sistema político a legitimar-se pela deliberação do processo comunicativo. Essa é a razão para que política seja constituída a partir dos argumentos capazes de garantir as condições necessárias para que os cidadãos possam expor suas opiniões e entendimentos acerca dos diversos temas previstos pelo Estado democrático de direito.

\section{Considerações finais}

Como tentei demonstrar em outro contexto de reflexão,

a sociedade precisa rearticular seu vínculo com a racionalidade comunicativa e com o mundo da vida, restabelecendo, desta forma, o potencial crítico de racionalidade minimizado pelo domínio de uma cultura estrategicamente racionalizada (GOMES, 2007, p. $153)$.

Para tanto, o diálogo crítico pode possibilitar novas formas de entendimento e de perspectiva social, pois não se trata apenas de "uma conversa entre as diferenças de modo que elas coabitem sob o manto de uma falsa paz entre sistemas, organizações, crenças" mas,

ao contrário, [de] um processo argumentativo no qual se expõem pontos de vista que podem ser excludentes com relação a alguns princípios mínimos e universais, condizentes com a condição humana (GOERGEN, 2010, p. 25). 
Trata-se de um processo formativo, complexo e tenso em que convivem as instâncias do sistema e do mundo da vida, sob o jugo das relações de poder presentes nas diversas formas de organização social. Nesse aspecto, a formação política torna-se decisiva, como explica o professor Pedro:

Encontramo-nos no limiar entre, de um lado, um mundo da vida totalmente manipulado ao gosto dos interesses hegemônicos, isolado da esfera pública e, de outro, um mundo da vida capaz de resistir e de preservar as relações entre a esfera pública e a esfera privada. Sabendo que o espaço da opinião pública depende dos impulsos vindos da elaboração privada de problemas sociais que têm ressonância na vida individual, cabe investir na formação da consciência política dos cidadãos. Essa é uma questão fulcral para a constituição da democracia e é nela que se torna perceptível o sentido mais profundo disso que Paulo Freire expressou ao dizer que toda educação é política (GOERGEN, 2008, p. 70).

Eis o desafio da consciência individual e coletiva, da convivência, do "entender-se", da vida democrática! Desafio, que segundo Goergen (2010) pode e deve ser enfrentado dialogicamente.

Para finalizar, Pedro, não poderia deixar de manifestar minha admiração, meu respeito e minha gratidão pela oportunidade de aprender contigo a manter, de um lado, os olhos sempre abertos à riqueza da tradição e, de outro, à perspectiva do que ainda é possível fazer pela educação e pela sociedade brasileira. 


\section{Referências}

GOERGEN, Pedro (org). Educação e Diálogo. Maringá: Eduem, 2010. 274p. . Ação Comunicativa, Democracia e Educação. In: SGRÓ, Margarita R.

(org.) Teoría Crítica de la Sociedad, Educación, Democracia y Ciudadanía. Tandil: Univ. Nacional del Centro de la Provincia de Buenos Aires, 2008. 469p.

GOMES, Luiz Roberto. Agir Comunicativo, Diálogo e Educação. In: GOERGEN, Pedro (org). Educação e Diálogo. Maringá: Eduem, 2010. 274p. . Educação e consenso em Habermas. Campinas: Alínea, 2007. 160 p.

HABERMAS, Jürgen. Direito e democracia: entre facticidade e validade. v. 1. Trad. Flávio Beno Siebeneichler. Rio de Janeiro: Tempo Brasileiro, 2003a. $354 \mathrm{p}$.

Direito e democracia: entre facticidade e validade. v. 2. Trad. Flávio Beno Siebeneichler. Rio de Janeiro: Tempo Brasileiro, 2003b. 352p.

- Teoría de la acción comunicativa I: racionalidad de la acción y racionalización social. Madrid: Editora Taurus, 1999a. 517p.

. Teoría de la acción comunicativa II: crítica de la razón funcionalista. Madrid:

Taurus, 1999b. 618p.

MÜHL, Eldon; ZUIN, Antonio S.; GOMES, Luiz Roberto (org.) Teoria Crítica, Filosofia e Educação: homenagem a Pedro Goergen. Passo Fundo: Edupf; Maringá: Eduem, 2014. 450 p.

PETERS, B. Die Integration moderner Gesellschaften. Frankfurt am Main: Suhrkamp, 1993. 455 p. 